\title{
Editorial
}

\author{
Judith Richards \\ Editor \\ doi:10.3396/ijic.V4i1.001.08
}

My task as incoming Editor has been greatly facilitated by the hard work and dedication of my predecessor Gertie van Knippenberg-Gordebeke. My warmest thanks to her for getting the Journal into such an excellent shape, and setting the foundations for the next step.

The IJIC now moves forward as a fully fledged and operational electronic Journal. This exciting venture, developed under the watchful eyes of our colleagues in Malta, will enable the Journal to receive electronic submissions, automatically acknowledged, facilitate the review and tracking processes, and help us to move to faster and more regular publishing. An International Journal relies on the quality of articles it receives. Please keep them coming!!

\section{A farewell from the outgoing Editor}

31 August 2007 was the $20^{\text {th }}$ anniversary of IFIC. Two years after the Federation was created, the launch of the first IFIC Newsletter in 1989 was a reality. It had 8 pages and I would like to share some text from the editorial of that issue, written by the editors: Professor Graham Ayliffe from the United Kingdom and Coby Paardekooper from the Netherlands.

"This Newsletter will be an important link between the Board and the members of the Federation in the intervals between delegate meetings, and will appear initially once a year, but it is hoped the number of issues will be increased to two or more.
The Newsletter will also be a forum for reports of projects of infection control in developing countries. We invite anyone with experience of such projects to send their contributions to the editors. We are particularly interested in receiving letters or comments from members about their particular problems. We hope that by publishing your ideas and experiences a useful exchange can be achieved between our members."

Internationally we now use the words Infection Prevention instead of Infection Control, and Healthcare Associated Infections rather than Nosocomial Infections. However, the basics of prevention and control remain the same as 20 years ago.

The Newsletter has also evolved, and is now a Journal providing its readers with a variety of articles, including scientific studies as well as reports from the field.

The success of an international publication is only possible with the reports and articles it receives from physicians, nurses, and all healthcare workers who take the time to share their experiences with us.

'As the outgoing Editor-in-Chief, I would like to thank all those who supported IFIC over the past 20 years, and urge you to continue sending your contributions to the Journal'.

\section{Gertie van Knippenberg-Gordebeke}

